\title{
Climate Policies with Burden Sharing: The Economics of Climate Financing
}

\author{
Julia M. Puaschunder*
}

The New School, Department of Economics, Schwartz Center for Economic Policy Analysis, 6 East $16^{\text {th }}$ Street, $11^{\text {rd }}$ floor 1129F-99, New York, NY 10003, USA,

Julia.Puaschunder@newschool.edu, T 0012122295700 4905, M 001917929 7038, F

001212229 5724, http://juliampuaschunder.com/

Columbia University, Graduate School of Arts and Sciences, $116^{\text {th }}$ Street Broadway, New York,

New York 10027, USA, Julia.Puaschunder@ columbia.edu

\begin{abstract}
*Financial support of the Eugene Lang College, Fritz Thyssen Foundation, the Janeway Center Fellowship, New School for Social Research, Prize Fellowship and the University of Vienna is gratefully acknowledged. The author declares no conflict of interest. The author thanks Professor Willi Semmler, Director Dr. Elena Rovenskaya and Dr. Sergey Orlov for most generous share of expertise and excellent feedback on the presented ideas and/or earlier versions of this paper. All omissions, errors and misunderstandings in this piece are solely the author's.
\end{abstract}




\begin{abstract}
The maintenance of a favorable climate accounts for the most challenging contemporary global governance predicament that seems to pit today's generation against future world inhabitants. In a trade-off of economic growth versus sustainability, a broad-based international coalition could establish climate justice. As a novel angle towards climate justice, the following paper proposes (1) a well-balanced climate mitigation and adaptation public policy mix guided by micro- and macroeconomic analysis results, and (2) a new way of funding climate change mitigation and adaptation policies through carbon tax and broad-based climate bonds that also involve future generations. Contemporary climate financing strategies (e.g., Sachs Model) are thereby added into Integrated Assessment Models of the Nordhaus Type. Overall, the paper strives to delve deeper into a discussion of how market economies can be brought to a path consistent with prosperity and sustainability. Finding innovative ways how to finance climate abatement over time coupled with future risk prevention as well as adaptation to higher temperatures appears as an innovative and easily-implementable solution to nudge overlapping generations towards climate justice in the sustainability domain.
\end{abstract}

Key words: Climate bonds, Climate change, Climate change adaptation and mitigation, Climate justice, Intergenerational burden sharing, Intertemporal discounting, Nonlinear model predictive control, Social discounting alternatives, Public policy 


\section{Exposé}

The maintenance of a favorable climate accounts for the most challenging contemporary global governance predicament that seems to pit today's generation against future world inhabitants in a trade-off of economic growth versus sustainability. The following paper starts with a review survey of the current climate policies (e.g., cap \& trade, carbon tax, green energy) outlining that the burden of climate change aversion - including the cost of mitigation and adaptation is unevenly distributed by falling mostly on the current generation. The excess burden for current generations has also been implicit in the work of the typical Integrated Assessment Model, IAM, (Nordhaus 2008), contemporary threshold as well as other mitigation and adaptation models, e.g., social cost of carbon. Innovative intertemporal fiscal policy approaches (e.g., of Jeffrey Sachs) will guide the development of a basic framework employing the IAM to study how an efficient and fair allocation of efforts towards mitigation and adaptation can be achieved. The empirical investigation will introduce elements of the intertemporal burden sharing model, by a Policy-Mix of Carbon Tax and Climate Bonds. Preliminary work of this type can be found in Sachs (2014), which will be integrated into a large scale IAM. Starting with an overlapping-generations framework, the proposed paper is targeted at solving the climate change abatement aversion in the fear of costs curbing economic growth which offers some innovative ideas in a continuous time framework with finite horizon. The current generation thereby mitigates climate change financed through carbon tax and bond issuing to remain financially as well off as without mitigation while improving environmental well-being of future generations. This intergenerational tax-and-transfer policies turn climate change mitigation into a Pareto improving strategy. This elementary but very innovative model by Sachs (2014) will be integrated in contemporary growth and economic climate models in order to analyze how a new way of funding, climate bonds, can be phased into climate policies to obtain socially optimal solutions in an IAM. A starting point of this large scale model is in particular the model by Klasen et al. (2015), which includes both the allocation of funds to mitigation and adaptation as well as funding those costs through climate bonds. To solve, calibrate and test such a new model of climate change policies and to show that such a debt augmented growth model stays within the bounds of a sustainable fiscal policy will help solve complex dynamic optimization problems with different nonlinearities for a finite decision horizon. The paper will thereby analyze micro- and macroeconomic insights on the wellbalanced harmonization of climate change mitigation and adaptation in order to provide public policy recommendations. As a novel angle towards climate justice, the paper overall offers as outcomes: (1) the introduction of IAM - into a large scale - as a way to derive behavioral climate policies. (2) Climate bonds introduced as a means of intergenerational climate change burden sharing to elicit future-oriented climate justice for posterity. (3) A well-balanced climate mitigation and adaptation public policy mix guided by macroeconomic analysis results. Overall, shifting the costs for climate abatement to the recipients of the benefits of climate bonds appears as novel, feasible and easily-implementable solution to nudge overlapping generations towards future-oriented loss aversion. Adding onto the contemporary idea and practice of carbon tax and climate bonds, the proposed paper shows how this practice can be given some foundation in the context of large scale IAM models with a larger role of the public sector. Alongside providing incentives to channel funds into climate policies, the article also retrieves information on the interplay of climate change mitigation and adaptation policies for ensuring sustainable growth. 


\section{Introduction}

Climate change accounts for one of the most pressing problems in the age of globalization as for exacerbating more complex risks than ever before. As never before in history since the birth of the earth, there is an environmental sensitivity to economic growth (Centeno and Tham 2012; Rovenskaya 2005; The World Economic Forum Report 2015). While classic economics portrayed balancing the interests of different generations as ethical problem of competitive markets requiring governance for intergenerational transfers and some economists even opposed discounting of future utilities (Allais 1947; Harrod 1948; Ramsey 1928); climate change has leveraged intergenerational equity as contemporary challenge of modern democracy and temporal justice an ethical obligation for posterity.

Uncertainty arising in assessment of economic growth in relation to climate change creates an unprecedented predicament for scientists and global governance technocrats (Rovenskaya 2008). Intertemporal questions arise whether to invest in abatement today - in order to prevent negative effects of global warming - or to delay investment until more information on climate change is gained (Rovenskaya 2008). In general, resources are balanced across generations by social discounting to weight the well-being of future generations relative to those alive today. Regarding climate justice, current generations are called upon to make sacrifices today for future generations to cut carbon emissions to avert global warming (Sachs 2014). Climate change mitigation at the expense of lowered economic growth seems to pit the current generation against future ones. Costly climate change abatement prospects are thus hindering currently necessary action on climate change given a shrinking time window prior to reaching tipping points that make global warming irreversible (Oppenheimer, O'Neill, Webster and Agrawal 2011).

As a novel alternative, Sachs (2014) proposes to fund today's climate mitigation through an intertemporal fiscal policy mix backed by climate bonds and carbon tax (Marron and Morris 2016). Bonds are debt investment in which investors loan money to an entity, which borrows the funds for a defined period of time at a variable or fixed interest rate. Bonds are primarily used by companies, municipalities, states and sovereign governments to raise money and finance a variety of future-oriented long-term projects and activities. This solution appears as real-world relevant means to tap into the worldwide USD 80 trillion bond market in order to fund the incentives to a transition to a sustainable paths (Flaherty, Gevorkyan, Radpour \& Semmler 2016; World Bank 2015). Carbon tax will also be introduced. Sharing the costs of climate change aversion between and across generations appears as important strategy to instigate immediate climate change mitigation through incentivizing emission reduction and provide adaptation (Puaschunder 2016a). Overall this turns climate change burden sharing into a Pareto improving option over time (Puaschunder 2016b). 
Mitigation and adaptation policies against climate risk: Recent IPCC research, international conferences on climate change and fund raising activities to combat global warming stress now that it is advisable to pursue both mitigation as well as adaptation policies (Greiner, Grüne and Semmler 2009, 2012; Flaherty et al. 2016). While climate justice will require both, climate change mitigation and adaptation, concurrently, no macroeconomic model exists to date that considers both approaches at once (Greiner, Semmler and Mette 2008). In addition, we lack information on the possible interdependencies, tradeoffs and reciprocal influences between climate change mitigation and adaptation (Bernard, Greiner and Semmler 2012). Therefore, the climate change mitigation and adaptation practices that are already in place - or are planned to be established - that help to buffer climate risk arising from weather extremes such as sea level rise, flooding, severe droughts, desert formation, storms, and hurricanes will be captured and analyzed in order to derive real-world relevant public policy recommendations on climate justice implementation.

Climate justice and burden sharing: While intergenerational burden sharing on climate change is a novel economically superior strategy and real-world relevant emergent risk prevention means (Centeno et al. 2013); we currently lack information on the impact of climate mitigation through debt on economic growth and the model's sustainability over time. Emissions trading schemes (ETS) and carbon tax policies are widely discussed as viable mitigation strategies, the revenue from which might then be used for adaptation efforts (Flaherty et al., 2016). The paper therefore builds on Sachs' (2014) intergenerational burden sharing idea by presenting a baseline and 2-phase policy intervention climate change burden sharing model through fiscal policy (with bond issuing and taxation) and reflect the implementation regarding contemporary finance and growth models with respect for maximizing utility of the model (Chiarella, Hsiao and Semmler 2007).

Empirically, the a DICE-type model of neoclassical economic growth theory and global warming should employ a simple Nordhaus type Integrated Assessment Model (IAM), to be calibrated by empirical facts in order to outline that there is a better way to deal with this problem (Nordhaus, 1994; Nordhaus \& Boyer, 2001). The implementation of climate change avoidance, and the adaptation against the coming climate risk seem to pit today's against future generations in the trade-off of economic growth versus sustainability.

Starting with a recent paper by Jeffrey Sachs (2014), and building in a direct carbon tax, is a novel angle towards climate justice that is introduced in order to find a behavioral economics solution to elicit future-oriented loss aversion. First, in an overlapping-generations type model and then as a continuous time IAM, the following paper elucidates climate change abatement and mitigation policies which lead to a fairer solution across generations. Building on preliminary results, the article provides real-world relevant means how to implement climate justice on a long-term scale (Flaherty et al. 2016). The integrated multi-stage climate model helps analyze how public finance can help, through green bonds, to fund climate policies that 
phase out fossil fuel energy and phase in renewable energy (Puaschunder, 2016). The current generation mitigates climate change, through a carbon tax, and provides infrastructure against climate risk financed through climate bonds to be paid by future generations. Since for future generations the currently created externalities from economic activities - the effects of $\mathrm{CO}_{2}$ emissions - are removed, this entails that the current generations remain financially as well off as without mitigation while improving environmental well-being of future generations. As Sachs (2014) shows, this intergenerational tax-and-transfer policy turns climate change mitigation and adaptation policy into a Pareto improving strategy. The theoretical model devices and solution techniques exist nowadays that can help to solve those models with regime changes. The calibration of the simple model is attempted by studying the types of bonds issuing that would achieve such goals. In addition, financial market practitioners should be interviewed to explore the more complicated bond issuing practices involved. In this context, it could also be tested if the climate change debt adjusted growth model stays within the bounds of a sustainable fiscal policy. Shifting the costs for climate abatement to the recipients of the benefits of climate bonds appears as novel, feasible and easily-implementable solution to nudge many overlapping generations towards future-oriented loss aversion in the sustainability domain in order to derive mitigation policies and communication strategies for a fairer and feasible climate solution.

\section{Climate Justice}

Society as a whole outlasts individual generations. Pareto optimality for society over time differs from the aggregated individual generations' preferences. As the sum of individual generations' preferences does not necessarily lead to societally favorable outcomes over time (Bürgenmeier 1994; Klaassen and Opschoor 1991), discounting based on individual generations' preferences can lead to an unjust advantage of living generations determining future living conditions (Rawls 1971). In general, intergenerational balance is therefore accomplished through individual saving decisions of the present generation (Bauer 1957). Policies curbing preferences and taxes distributing welfare between the present and future generation may, however, decrease economic growth.

In order to avoid governmental expenditure on climate change hindering economic growth (Barro 1990); Sachs (2014) introduces financing climate change mitigation through debt to be paid back by future generations through taxation as a novel means to amend individual saving preferences in favor of future generations (Marron and Morris 2016). Carbon taxes can raise substantial revenue until the economy is largely decarbonized (Marron and Morris 2016). In Sachs (2014) 2-period model, one generation works in period 1 and retires in period 2. Part of the disposable wage income is saved for consumption in the second period. $\mathrm{CO}_{2}$ emission mitigation imposes immediate costs onto current generations and reduces wages. Greenhouse gas concentrations in period 2 are determined by the emissions in period 
1. Wages of the young in the second period are reduced by climate change dependent on greenhouse gas levels. Disposable labor income of the young equals market wage net of taxes. Sachs (2014) proposes to mitigate climate change by debt to be repaid by tax revenues on labor income in the future. Leaving the current generation with unchanged disposable income allocates the burdens of climate change mitigation across generations without the need to trade off one generation's well-being for another's. While today's young generation is left unharmed, the second period young generation is made better off ecologically. Taxes on later generations are justified as for the assumed willingness of future generations to avoid higher costs of climate change prevention and environmental irreversible lock-ins. Overall this taxand-transfer mitigation policy is thus Pareto improving across generations. All generations are better off with mitigation through climate bonds as compared to the business-as-usual (BAU) non-mitigation scenario (Sachs 2014). While future generations enjoy a favorable climate and averted environmental lock-ins; the current populace does not face drawbacks on economic growth.

Greiner, Semmler, and Gong (2005) introduce a time series perspective on economic growth for better specifying microeconomic behavior of economic agents in order to forecast growth and derive development policies. Greiner et al.'s (2005) growth models connect public economics with growth theory. Based on Barro (1990) and Futagami, Morita and Shibata (1993), Semmler, Greiner, Diallo, Rajaram and Rezai (2011) model economic growth with regard to public infrastructure investment, whereby public and fiscal policies support sustainability. In their composition of public expenditures, the government undertakes productive investment that raises the marginal product of capital and stimulates economic growth. Paying attention to fiscal regimes and the composition of public spending, Semmler et al. (2011) consider the composition of public spending including social investment. Semmler et al.'s (2011) model allows deriving implications for growth and welfare for overlapping generations in order to underline the inter-temporal consequences and trade-offs of climate policies. The model enables governments to acquire debt in their climate change mitigation as a part of the government budget. At the same time, a carbon tax on top of the existing tax system that will increase the overall economic burden on the tax system should be used to reduce the burden of climate change and encourage economic growth through subsidies (Chancel \& Piketty 2015). Other options to promote growth include investing in infrastructure, education, research and development, and other activities that expand the productive capacity of the economy (Marron \& Morris 2016). Public investment is turned into public capital for raising productivity of market production through transport systems (roads, bridges, harbors) and utilities (for example water supply); facilitating the formation of human capital via health services and education.

Fiscal policy ensures debt sustainability, when governments can borrow to undertake public investment (Semmler, Greiner, Diallo, Rezai, and Rajaram 2007). When the government 
issues bonds that 'borrow' from future generations for undertaking public investments for carbon emissions, the implication of this type of expenditure is that along the transition path, this will raise the growth rate of the overall public infrastructure (Gevorkyan and Semmler 2015; Greiner et al. 2005). This higher level brings a distortion into the model by raising the marginal product of private capital. As a consequence, the investment share is increased and the growth rate of consumption rises implying higher welfare after a sufficiently long adjustment period. Note that this also leads to higher growth of physical and human capital and these growth effects only hold on the transition path (Klasen, Maurer, Semmler and Bonen 2015). In the long-run, higher public investment leads to higher levels of output and consumption but does not affect the growth rate of endogenous variables (Semmler et al. 2011).

Since here borrowing equals loans or issuing of bonds to be paid back by future generations, the government must pay back debt plus interest payments by raising taxes (Klasen et al. 2015). Countries must check whether fiscal policies are such that they fulfill the inter-temporal budget constraint, whereby per-capita government debt at time zero must equal the discounted stream of future primary surpluses. Sustainability is ensured if the government adjusts the primary surplus to GDP ratio to variations in the debt-GDP ratio - a test independent of the interest rate conditions. Bohn (1998) suggests to test whether the primary deficit-to-GDP ratio is a positive linear function of the debt-to-GDP ratio. Testing a no-Ponzi game condition, public (net) debt at time zero must equal the expected present value of future primary surpluses.

Building on Semmler's and Klasen's modeling of economic costs and benefits of public investment in climate change-adaptive infrastructure outlining the trade-off between mitigation and adaptation and a dynamic, nonlinear model of these trade-offs in a closed economy (Klasen 2012); Klasen et al. (2015) modeled real-world climate change mitigation and adaptation trade-offs. The link of climate change mitigation and adaptation initiatives at the regional level helped develop real world-relevant climate change policy prescriptions for governments, private sector stakeholders as well as IPCC executives. Based on the preliminary findings of the developing countries' optimal policy mix to combat climate change (Klasen et al. 2015), the established framework of costs and benefits of climate change mitigation and adaptation infrastructure derived implications how to balance global warming responses with economic growth postulates (Greiner and Semmler 2008; Klasen 2012; Klasen et al. 2015; Klasen and Waibel 2012).The model innovatively took into account both adaption and mitigation policies. The IAMs used a macroeconomic modeling approach that Semmler and colleagues employed in optimal climate change policy recommendations with respect for country-specificities in order to design and calibrate climate change adaptation and mitigation IAM and the optimal mitigation and adaptation policy mix with real-world relevance for climate protection (Greiner, Grüne and Semmler 2010, Greiner and Semmler 2005; Klasen et al., 2015). In addition, the model calibrated the development versus mitigation versus adaptation 
policy mix in order to retrieve efficient climate modeling strategies leading to important contributions for the international climate negotiations on the optimal climate policy mix. Using macro- and microeconomic modeling and building on the DICE Model, the outlined costs and benefits of mitigation and adaptation strategies are key in determining security strategies for vulnerable cities, communities and countries and protect them from the variegated climate change risks (Nordhaus, 1994). The results achieved help multivariate stakeholders for shaping economic growth and sustainable development. The described models will become the basis to be used for modeling climate change burden sharing through bonds. Another important aspect of this type of work will be to also allow for compensation if the cost of mitigation has very uneven distributional effects.

\section{Funding Climate Policies}

In order to implement an intra-and intergenerationally fair solution to ensure climate justice, a three-regime approach is proposed. Intragenerationally the issue is how a fair carbon tax can be achieved. Intergenerationally the current generation may require that future generations also contribute to the cost of climate change.

\section{Variant 1: Climate Bonds and Three Phases}

A three phase model is outlined that can deal with the intertemporal aspect. In this three phase model current costs of climate change abatement is partly shifted to future generations through bonds to be financed by taxing future generations. Though future generations will face some tax, they will also benefit in the sense that the externalities from $\mathrm{CO}_{2}$ emission and climate change are removed. A simplified model version can be sketched as following.

The Model phase 1 of economic growth without mitigation effort is called business-asusual (BAU). We call this phase 1. The model economy of this type features households in a production economy who choose consumption in order to maximize a discounted stream of utility. Economic households maximize the discounted stream of utility arising from consumption, $C_{t}$, is subject to a budget constraint. The utility of this phase is maximized by:

$\int_{\mathrm{t}=0}^{\mathrm{T}} \mathrm{e}^{-\rho_{\mathrm{t}}} U_{t}\left(C_{t}\right) \mathrm{dt}$

in which $\rho>0$ is the discount rate.

Economic activities generate emissions of greenhouse gases, as a by-product of capital used in production and expressed in $\mathrm{CO}_{2}$ equivalents. Environmental economics implies that a higher capital stock goes along with higher emissions (Hettich 2000; Smulders 1995). Emissions of greenhouse gases indirectly affect the climate of the earth leading to higher surface temperature and weather extremes, like flooding, heatwaves, storms, desert formation and so on. 
In the model of phase 1, with an optimization horizon $\left[\mathrm{T}_{0}, \mathrm{~T}_{1}\right]$, the BAU approach, no climate change mitigation effort $A_{t}$ is employed. It is a laissez-faire solution, in which there is environmental damage and no climate change mitigation. The evolution of per-capita capital over time is thereby determined by the following differential equation that represents the budget constraint of a household:

$\dot{K}_{t}=D_{t} * Y_{t}-C_{t}-(\delta+\mathrm{n}) * K_{t}, \mathrm{~K}(0)=\mathrm{K}_{0}$

with the per-capita production $Y_{t}$ accounting for environmental damage $D_{t}$ being reduced by consumption $C_{t}$ and per-capita capital $K_{t}$ accounting for the depreciation of capital $\delta$ andpopulation growth $\mathrm{n}$. In the stylized model, growth leads to the increase of industrial emission (Rovenskaya 2005).

In the BAU model, there are no climate change abatement activities. Yet, environmental damage reduces output by

$D_{t}=\left(\mathrm{a}_{1} * M_{t}^{2}+1\right)^{-\Psi}$,

with $\mathrm{a}_{1}>0$, being a function that negatively depends on the temperature on earth as deviations from the equilibrium average surface temperature have feedback effects that influence the reflection of incoming energy (e.g., snow and ice reduction and water evaporation lead to a smaller amount of solar radiation tending to increase the earth temperature even further), $\Psi>$ 0 and $M_{t}$ being the greenhouse gas concentration in the atmosphere (Henderson-Sellers and McGuffie 1987; Nordhaus 2008; Schmitz 1991). The effect of emissions to raise the greenhouse gas concentration, $M_{t}$, in the atmosphere is determined by

$\dot{\mathrm{M}}_{t}=\beta * E_{t}-\mu * M_{t}$

in which emissions $E_{t}$ factored by $\beta \in(0,1)$, which is the part of greenhouse gas emissions that is not taken up by oceans, are reduced by $\mu \in(0,1)$ as the inverse of the atmospheric lifetime of greenhouse gases or decay rate of greenhouse gases in the, see Intergovernmental Panel on Climate Change (2001).

The greenhouse gas emissions are described by

$E_{t}=\left(\mathrm{a} * K_{t}\right)^{\gamma} *\left(\frac{1}{\mathrm{~d} * A_{t}+\mathrm{p}}\right)^{\gamma}$

with $K_{t}$ being the stock of capital, $\gamma>0$ representing the exponential growth rate in the emission function and the parameter $\mathrm{a}>0$ as constants. Emissions are a function of per-capita capital, $K_{t}$, relative to per-capita climate change abatement activities $A_{t}$ as indicated by the efficiency factor $\left(\frac{1}{d * A_{t}+\mathrm{p}}\right)^{\gamma}$, whereby $\mathrm{d}$ and $\mathrm{p}$ are parameters (Greiner et al. 2009, 2012). During BAU, the abatement $A_{t}$ is 0 . The technology index a describes how polluting a given technology is insofar as the larger a is given a stock of capital and abatement, the higher the emission is, which implies a relatively polluting technology (Greiner et al. 2009, 2012).

In contrast to the BAU scenario, Model phase 2, with an optimization horizon in (1.1) of $\left[T_{1}, T_{2}\right]$, proposes an externality control to mitigate climate change through bonds extending 
Sachs (2014) and Greiner et al. (2012). In order to overcome output decline in the wake of externality control and the need for capital stock to produce renewable energy, social expenditure improving welfare regarding climate change is considered by issuing climate change mitigation bonds. Instead of assuming a lump-sum tax or a tax on consumption used to finance abatement spending, climate change burden sharing debt bonds are thereby issued by current generations, who are immediately compensated for their climate change abatement costs, to be paid off by taxing future generations. In model 2 the government sells climate change mitigation bonds to reimburse the abatement costs $A_{t}$ from period $\left[\mathrm{T}_{1}, \mathrm{~T}_{2}\right]$, when climate change abatement bond issuing stops and climate change mitigation bond repayment sets in through taxation in model phase 3. Overall, there is environmental damage but mitigation that is reimbursed to be paid back by later generations.

As in model 1, the greenhouse gas emission $M_{t}$ is determined by (1.4). In $K_{t}(1.2)$ the production function $Y_{t}$ denoting per-capita output is given by

$Y_{t}=\widetilde{A_{t}} * K_{t}^{\alpha}$,

with $\alpha \in(0,1)$ being the capital share and $\widetilde{A_{t}}$ being an efficiency index constant normalized to 1. The greenhouse gas emissions are, as in Model 1, described by (1.5) but with $A_{t}>0$.

In model 2 bonds are issued from the beginning to period to period $\mathrm{T}_{2}$ arising $\dot{\mathrm{B}}_{t}=r_{t} * B_{t}+g_{t} * B_{t}(0)$

As public debt $g_{t}$, where $r_{t}$ is the interest rate paid on climate change abatement bonds. $B_{t}(0)$ denotes the starting point of public debt at time 0 . We now have a model with three state variables and the abatement cost being reimbursed by the issuing of public bonds. Note that in this period the government subsidizes the generation to compensate for the upfront costs of climate change mitigation. The government reimburses climate change aversion until a regime-change switching, when taxes become positive and later generations pay for earlier climate change abatement through taxation. The later generations are assumed to be willing to pay to avoid the higher costs of climate change relative to a BAU path.

In the Model phase 3, the optimization horizon in (1.1.) is $\left[T_{2}, T_{3}\right]$, when no further climate change abatement costs exist and the debt of bonds is to be repaid from period $T_{2}$ on, after switching to the model 3 , we then have instead of equation (1.7):

$\dot{\mathrm{B}}_{t}=r_{t} * B_{t}-T_{t_{\mathrm{N}}}$

Whereby $T_{t_{N}}=\tau \mathrm{Y}_{\mathrm{N}}$ is used for the repayment of bonds.

From that period on the capital stock over time, $\dot{K}_{t}$, is also reduced by $\tau_{t_{\mathrm{N}}}$ in

$\dot{K}_{t}=Y_{t}\left(1-\tau_{t_{\mathrm{N}}}\right)-C_{t}-\left(\delta+n_{t}\right) * K_{t}$

Note that in the model phase 3 neither an externality effect, $D_{t}$, nor climate change abatement cost, $A_{t}$, are present. There is no environmental damage but taxation for climate change abatement bonds repayment. Only the previously raised bonds of equation (1.7) will have to be repaid by the generation existing from that period on. These future generations will 
benefit from the absence of damages from externalities of previous periods. The negative externalities are removed by agents from the previous periods.

\section{Variant 2: Carbon Tax, Climate Bonds and Three Phases}

Next follows the research and solution strategy to deal with the issue when from model phase 2 on a carbon tax is also introduced, in addition to the climate bonds. The subsequent two model phases are very similar to the models phase 2 and 3 above and thus only the ideas need to be described here.

In the budget equation of the households in phase 2, equation (1.2), a carbon tax, representing an abatement cost, is introduced that reduces households' income. The tax rate and abatement effort affect equation (1.5) by increasing the denominator by the amount of the abatement effort. The complication is, however, that the tax rate should only be levied on the remaining polluting capital, and as the capital stock becomes more and more green capital the tax income and abatement effort will shrink and eventually disappear (see Moser, Prskawetz and Tragler 2011).

This carbon tax for the model phase 2 will be set to zero when model phase 3 is reached and only the tax rate for the model phase 3 generation that is repaying the bonds issued in phase 2 will affect the budget equation of the households. The repayment of the issued bonds will in this phase 3 decline the same way as described in equations (1.8) and (1.9). The phase by phase solution can also be obtained by further numerical calculus.

\section{Discussion and Future Research Directions}

Climate change presents specific risks and challenges associated with system failure. The very logic of increasing globalization carries problems that demand for a redesigning of governance structures and institutional arrangements that reduce the probability of such dangers arising (Centeno et al. 2013). For this, we first need to understand the nature of the danger. Fragile environmental conditions due to a missing information of systemic risks of climate change underline the importance of a whole-rounded understanding of climate change mitigation and adaptation to overcome future socio-economic losses and avert irreversible tipping points.

There is much literature on the economics of climate change, on causes of climate change, mitigation policies, such as cap \& trade, carbon tax, regulatory measures, and on adaptation (Bernard et al. 2012). The current research attempts to address in particular the funding a burden sharing of climate policies. A further literature review and studies have to be undertaken on the current discussion on sustainable finance and the diverse methods of funding of mitigation and adaptation policies. Particular emphasis will be given to the already existing literature, experiences and practices of issuing climate bonds and its relation to carbon 
tax. There is substantive literature generated through the IPCC research, international conferences on climate change and global warming abatement that stress the currently most urgent need for climate change mitigation and adaptation policies. The issue of sustainable financing of climate policies is less developed. A exploratory climate change literature analysis could clarify what contemporary notions of climate change risks are in order to retrieve a realeconomy based climate change risk definition.

Overall, our knowledge of climate change mitigation and adaptation interdependencies remains an open research gap important to be investigated in the eye of climate threats with enormous global impact. As we think about this topic, no single vantage point is sufficient by itself, and a genuine understanding of the problems and the possible solutions will require knowledge, expertise, and experience from multiple fields. Therefore, future research must analyze climate change risks inherent in global environmental conditions. International academic and practitioners' literature on climate change risk, climate mitigation and adaptation as well as climate justice should be reviewed. A thorough literature analysis will form a foundation of knowledge on climate change, climate mitigation and adaptation as well as climate justice approaches on an international scale.

A stakeholder-nuanced literature review will cover public and private, organizational and societal stakeholders to retrieve notions on global warming risks and climate change mitigation and adaptation in the international arena with a special focus on climate funding as well as bond solutions. The results will guide the descriptive analysis of climate change mitigation and adaptation strategies.

The theoretical insights gained could lead to a final semi-structured interview guide to explore climate risk notions and success factors to avoid climate change and gain climate justice. Practitioners' bond market actors and finance stakeholders may be recruited comprising of very many stakeholder groups such as banking executives (e.g., financial executives, managers, bank officials); fiduciaries (e.g., private equity, mutual funds, investment managers); institutional investors from central banks, governmental and rating agencies, universities; private investors (e.g., shareholders, etc.) from financial trade agencies; public policy specialists of global governance networks; labor union representatives; nongovernmental organizations (e.g., NGO executives) contacted online; international organizations (e.g., UN, World Economic Forum, Open Society Institute); academics (e.g., professors, assistants, $\mathrm{PhD}$ candidates) and media representatives (e.g., journalists, reporters). These activities will be oriented toward producing an interdisciplinary consensus on global climate change risks and formulate guidelines for future research on climate change mitigation and adaptation.

Subsequent exploratory descriptive and qualitative data collection on climate change mitigation and adaptation should clarify how climate change risks are defined and perceived by various stakeholder groups in order to retrieve a stakeholder-specific climate change risk 
definition with focus on climate justice, mitigation and adaptation. Contemporary notions and strategies of climate change risk mitigation will draw a real-economy relevant climate change risk mitigation strategy. What factors contribute to the success of risk mitigation and adaptation should be clarified in order to derive success factors of climate change risk mitigation and adaptation means and prospectively favourable interdependencies.

Future research may combine theoretical and empirical research featuring qualitative and quantitative methodology. After a literature review of climate change risk, climate justice and climate change mitigation and adaptation strategies, quantitative research should target at gaining an in-depth understanding of climate change risk mitigation, climate change stability implementation and climate adaptation in the international arena. Quantitative market analyses aim at capturing international climate change mitigation and adaptation interdependencies. The field-specific perspectives include nomenclature creation, literature reviews, quantitative and qualitative methods, and public policy information of experts and institutions.

The first research endeavors should develop our understanding of climate change risk through the analysis of specific climate threats. The task will be approached by case studies and expert interviews with the goal of developing a multidisciplinary methodological analysis of global climate risks to be proposed to be alleviated through financing solutions as well as recommendations of harmonious climate change mitigation and climate adaptation strategies.

Preliminary research should therefore aim at better understanding the structure, nature, and challenges of these complex interaction and feedback systems of climate, climate change mitigation and adaptation choices and elaborate how it can be funded. The complexity and number of interactions will also require a qualitative analysis on the challenges of climate policy funding. In this context it is also important to capture and map what regulatory and policy solutions exist and have been developed in response to climate crises. Academic studies should target climate change monitoring, inspection, and surveillance as well as climate change adaptation policies as the basis for further modelling.

In the climate change burden sharing model building, the underlying research question what sustainable financing methods of climate change financing would be in order to assist the implementation and management of climate stabilization. In deriving information on climate change mitigation implementation and management strategies, the question should be answered what institutions could issue and sustainable finance regimes manage climate change bonds. This information is essential in order to craft institutional climate change management strategies and define feasible market structures to issue and policies to support climate change bonds. All these endeavors will help following the greater goal to derive viable intertemporal policy strategies based on real market mechanisms. In addition, the fiscal sustainability of climate change bonds over time should be evaluated in order to estimate real- 
world relevant climate change mitigation market strategies in the finance sector based on future bond prospects.

The novel model gives rise to ethical questions concerning burden sharing of climate cost for the current generation and between current and future generations. The question is also are future generations willing to contribute to climate stability. While prevention is argued to face more resistance than clean-up of damages in public, given a loss averse world, the rational is to avert future environmental lock-ins and irreversible global warming tipping points at the expense of reversible overindebtedness (Kahneman and Tversky 1979). While capital is a replaceable asset and overindebtedness raises questions of temporal governmental budget issues, and possibly economic soft or hard landing scenarios, an irreversible global temperature rise and climate imbalances would result in unforeseeable threats to mankind. Imposing the financial costs of climate mitigation partly onto future world inhabitants for the trade-off of a decent world temperature may thus be justified in the light of the complete replaceability of capital and its non-perishable nature in contrast to natural tipping points and irreversibility of climate change that have been outlined by climate change experts (Oppenheimer et al. 2011). Avoiding to pit one generation against the other, earlier generations can enjoy better economic growth, while their descendants will benefit from a favorable climate mitigation policies and infrastructure.

Future research may compile contemporary evidence on the burden of climate change mitigation being unevenly heavy on current generations that has also been implicit in the work of the typical Integrated Assessment Model (Nordhaus), but also being covered in the threshold model (Greiner, Grüne and Semmler 2012; Klasen et al. 2015). Future research should introduce a new partial model, which works with intertemporal burden sharing to be integrated into a model of infrastructure against climate risk comprising of a better climate change mitigation and adaptation mix.

Building on contemporary modeling and empirical studies (e.g., Puaschunder, 2016a, b) on global warming as well as sensitivity and cost-benefit analyses of emission-constrained technological growth under uncertainty in natural emission (Rovenskaya 2005, 2008) but also adding novel insights derived from Sachs (2014), future research should employ a DICE-Model Nordhaus type IAM, to be extended and then calibrated by empirical facts. Solving the economic growth versus sustainability predicament that pits today's against future generations based on Jeffrey Sachs' work (2014), future work should propose a novel angle towards social environmental justice.

Starting with an overlapping-generations model converted into continuous time IAM, outstanding studies should study climate change abatement and adaptation in order to derive climate change bonds as fairer and socially more just climate solution across generations. In the model, the current generation mitigates global warming through carbon tax and climate bonds, the latter to be repaid by future generations. While the current generation suffers a 
small income loss as compared without mitigation, the future climate for posterior generations is ensured and thus their well-being improved.

A novel theoretical model and solution techniques will lead to an innovative and feasibly-implementable climate change growth model that considers also the contributions of future generations. While one can find longer decision horizons important for sustainability, a more extended infrastructure model of the Semmler et al. (2011) type can be developed that helps instigate action now for current climate change mitigation and future irreversible environmental damage reduction through bonds repayments in the future. In addition, the welfare effects of the enlarged model variants will be computed and compared. In the case of sustainability bonds, the optimal number of periods and when it is optimal to phase in sustainability bonds should be explored in order to derive recommendations when to switch to mitigation, tax rates and bond issuing and repayment. Thereby, the dynamics of the transition process regarding a regime switch from BAU to mitigation policy and to climate change bond repayments should be discovered.

Future research endeavors should survey the current scholarship on contemporary climate policies and their funding (e.g., cap \& trade, carbon tax, green energy). Here also climate change mitigation and adaptation strategies should be gathered in order to prepare the modeling and methodologies of systemic climate risk and climate analysis in the following.

Intergenerational climate change burden sharing through intergenerational fiscal policies and sustainable finance methods could be delineated in order to introduce carbon tax and climate bonds as novel approach to implement intergenerational climate justice. Based on preliminary work by Sachs (2014), an overlapping-generations model could be extended and converted into a continuous time model paying attention to economic growth, externalities, climate change mitigation funded through carbon tax and bond issuing. This intergenerational equity implementation turns climate change mitigation into a Pareto improving strategy. Future research should also explore international dimensions of climate change risk mitigation and adaptation efforts and their interdependencies. Comparisons of climate change risk reduction means on the international level will help derive insights for global governance experts on how to implement climate justice.

Climate change mitigation and adaptation study efforts should investigate how climate change is mitigated on the international level in order to derive international climate change prevention strategies. The adaptation efforts should be scrutinized on a global level in order to unravel interdependencies of climate change mitigation and adaptation on a worldwide basis. This may be done by economic market analyses featuring externality predictions and cross-market comparisons coupled with social network analyses.

Community research will present field-specific perspectives on systemic risk mitigation in the finance sector. Expert interviews will allow understanding aspect of climate change bond strategies that stakeholders find most relevant. Case studies on global climate risk mitigation 
will portray climate change abatement with attention to particular stakeholder perspectives in order to retrieve a real-world relevant climate strategy. Overall, all these endeavors will strengthen the research and design of climate, encourage interdisciplinary exchange on the contemporary complex climate agenda in strategic partnerships, as well as raise awareness and engage the broader international public on multiple climate regimes.

Future concrete data collection could feature semi-structured telephone or personal interviews with finance experts representing a stakeholder-range ${ }^{1}$. Expert interviews will gain a stakeholder-specific definition of climate change, climate risk, climate mitigation and adaptation as well as climate change bond strategies in the finance sector. The acquired information will present stakeholder-specific contemporary notions of climate change, climate change mitigation and adaptation efforts as well as their interdependencies. Revealing the common sense, but also stakeholder-specific nuances of climate change risk perceptions with a special focus on climate change mitigation solutions of the finance sector offers an invaluable opportunity to highlight unknown climate implementation strategies. This working part will include a meta-analysis of risk and its various meanings held by different constituency groups in order to provide the basis for global governance and public policy recommendations how to mitigate and adapt to global warming. A vital research exchange and scholar transfer between various stakeholder groups - featuring external quality control and results presentations - will help discuss risk definitions with colleagues prior to continuing to develop ideas and combine the lessons learned in approaches of the forming community around endeavors. The information retrieved will also help create a coherent set of papers on systemic climate change risks, mitigation and adaptation as well as policy briefings reflecting the different academic disciplines and viewpoints on the climate agenda. The data gathered should be quantitatively analysed by descriptive and multivariate methods in order to scrutinize the international climate risk mitigation and adaptation means. Network analyses will capture climate mitigation and adaptation differences to derive climate justice implementation recommendations.

In order to unravel climate change risk mitigation and adaptation success factors, economic market data should be analysed by descriptive and multivariate methods in order to derive an online interactive computer simulation tool. For instance, network analysis will allow investigating risk mitigation factors and climate adaptation interdependencies following the greater goal to outline prescriptive public policies to enhance climate justice. The analysis of climate change risk mitigation means will help develop recommendations on regulatory schemes. Coupled with the study of climate change adaptation strategies by institutions, industry actors and policy makers, the results will lead to practical guidelines on how to implement environmental sustainability. The gained insight on climate mitigation and

\footnotetext{
1 e.g., academics; banking executives; fiduciaries; institutional and private investors; international organizations; labor union representatives; media representatives; NGO officials; public policy specialists; public servants
} 
adaptation as well as the expert discussions and scholarly exchange on how to prevent systemic risks. In addition, an open access interactive online climate change simulation should be released as an attempt to map the contemporary climate efforts and regimes on a global scale to provide a possible avenue for future work.

Overall, these outlined research avenues should innovatively develop new interpretations, understandings and concepts of climate risks but also help deriving balanced approaches to implement climate justice and adapt to global warming. In compiling scholarship and theories on risk mitigation strategies in the climate action domain as well as by bringing together experts on climate risk from Europe and North America coupled with the financial sector insights on how to finance climate justice, the planned research will help create a central reference point and resources on aggregate information on the implementation and sophistication of climate justice.

The planned endeavors will elevate the importance of climate justice scholarship whilst deriving implications for climate stability. Emphasizing areas where to apply climate mitigation and where to promote climate adaptation strategies will help deriving practical implications for the private industry and public policy sector. Understanding the different climate risk attitudes but also shedding light on previously unknown climate mitigation and adaptation interdependencies will aid environmental sustainability to ensure a future mankind. For practitioners the prospective results will help lowering institutional downfalls of increasingly interconnected and fragile global networks. For academia, the endeavors will spearhead interdisciplinary research on climate justice and lead to invaluable resources on systemic risk with short-term innovative and long-term historic value for this generation and the following. 


\section{References}

Allais, M. (1947). Economie et intérét. Paris: Imprimerie Nationale.

Barro, R. (1990). Government spending in a simple model of endogenous growth. Journal of Political Economy, 98, 103-125.

Bauer, P.T. (1957). Economic analysis and policy in underdeveloped countries. Chapel Hill: Duke University Press.

Bernard, L., Greiner, A. \& Semmler, W. (2012). Agricultural commodities and their financialization. SSRN working paper accessed November $11^{\text {th }}, 2015$ at http://papers.ssrn.com/sol3/papers.cfm?abstract_id=2009733

Bohn, H. (1998). The behavior of U.S. public debt and deficits. Quarterly Journal of Economics, 113, 949-963.

Bürgenmeier, B. (1994). Environmental policy: Beyond the economic dimension. In B. Bürgenmeier (Ed), Economy, Environment, and Technology: A Socio-Economic Approach, pp. 166-175. New York: Armonk Sharpe.

Centeno, M.A., Creager, A.N., Elga, A., Felton, E., Katz, St.N., Massey, W.A., \& Shapiro, J.N. (2013). Global systemic risk: Proposal for a research community. Princeton University: Princeton Institute for International and Regional Studies working paper.

Centeno, M.A., \& Tham, A. (2012).The emergence of risk in the global system. Princeton University working paper.

Chancel, L. \& Piketty, Th. (2015). Carbon and inequality: From Kyoto to Paris. Paris, France: Paris School of Economics.

Chiarella, C., Hsiao, C.Y. \& Semmler, W. (2007). Intertemporal investment strategies under inflation risk. Quantitative Finance Research Centre Working Paper, 192.

Flaherty, M., Gevorkyan, A., Radpour, S. \& Semmler, W. (2016). Financing climate policies through climate bonds. New York: The Schwartz Center for Economic Policy Analysis, Unpublished working paper \#3, Forthcoming: Research in International Business and Finance, 2016.

Futagami, K., Morita, Y. \& Shibata, A. (1993). Dynamic analysis of an endogenous growth model with public capital. Scandinavian Journal of Economics, 95, 607-625.

Gevorkyan, A. \& Semmler, W. (2015). Oil price, overleveraging and shakeout in the shale energy sector: Game changers in the oil industry. SSRN working paper accessed November $11^{\text {th }}, 2015$ at http://papers.ssrn.com/sol3/papers.cfm?abstract_id=2673066

Greiner, A., Grüne, L. \& Semmler, W. (2009). Growth and climate change: Threshold and multiple equilibria. Schwartz Center for Economic Policy Analysis, Working Paper 2009-7.

Greiner, A., Grüne, L. \& Semmler, W. (2010). Growth and climate change: Threshold and multiple equilibria. In J.C. Cuaresma, T. Palokangas \& A. Tarasyev (Eds.), Dynamic Systems Economic Growth and the Environment. New York: Springer.

Greiner, A., Grüne, L. \& Semmler, W. (2012). Economic growth and the transition from nonrenewable to renewable energy. SSRN working paper accessed March $20^{\text {th }}, 2015$ at http://papers.ssrn.com/sol3/papers.cfm?abstract_id=2098707

Greiner, A., Koeller, U. \& Semmler, W. (2005). Testing sustainability of German fiscal policy: Evidence for the period 1960-2003.CESifo Working Paper 1386. 
Greiner, A. \& Semmler, W. (2005). Economic growth and global warming: A model of multiple equilibria and threshold. Journal of Economic Behavior and Organization, 57, 4, 421430.

Greiner, A. \& Semmler, W. (2008). The global environment, natural resources, and economic growth. Oxford: Oxford University Press.

Greiner, A., Semmler, W. \& Gong, G. (2005). The forces of economic growth: A time series perspective. Princeton: Princeton University Press.

Greiner, A., Semmler, W. \& Mette, T. (2008). An economic model of oil exploration and extraction. SSRN working paper accessed November $11^{\text {th }}, 2015$ at http://papers.ssrn.com/sol3/papers.cfm?abstract_id=1264967

Grüne, L., Maurer, H. \& Semmler, W. (2015). Climate policies with mitigation and adaptation: Preliminary results. Workshop presentation, University of Göttingen, Göttingen, Germany, January 21, 2015.

Grüne, L., Semmler, W. \& Stieler, M. (forthcoming). Using Nonlinear Model Predictive Control for dynamic decision problems in economics. Journal of Economic Dynamics and Control.

Grüne, L. \& Stieler, M. (2014). Asymptotic stability and transient optimality of economic MPC without terminal conditions. Journal of Process Control, 24, 8, 1187-1196.

Harrod, R.F. (1948). Towards a dynamic economics. London: Macmillan.

Henderson-Sellers, A. \& McGuffie, K. (1987). A climate modelling primer. New York: Wiley.

Hettich, F. (2000). Economic growth and environmental policy. Cheltenham Glos: Edward Elgar.

Intergovernmental Panel on Climate Change (IPCC) (2001). Climate change 2001: The scientific basis. IPCC third assessment report of working group 1.

Kahneman, D. \& Tversky, A. (1979). Prospect theory: An analysis of decision under risk. Econometrica, 47, 2, 263-291.

Klaassen, G.A.J. \& Opschoor, J.B. (1991). Economics of sustainability or the sustainability of economics: Different paradigms. Ecological Economics, 4, 93-115.

Klasen, St. (2012). Gender, growth and adaptation to climate change. In B. Cela, I. Dankeman \& J. Stern (Eds.), Powerful Synergies: Gender Equality, Economic Development and Environmental Sustainability, pp. 59-69. New York: United Nations Development Programme.

Klasen, St., Maurer, H., Semmler, W. \& Bonen, A. (2015). Climate policies with mitigation and adaptation: Preliminary results. Workshop presentation, University of Göttingen, Göttingen, Germany, January 21, 2015.

Klasen, St. \& Waibel, H. (2012). Vulnerability to poverty: Theory, measurement, and determinants, with case studies from Thailand and Vietnam. London: Palgrave.

Marron, D.B. \& Morris, A.C. (2016). How to use carbon tax revenues. Washington, D.C.: Tax Policy Center Urban Institute \& Brookings Institution.

Maurer, H., Preuss, J.J. \& Semmler, W. (2013). Optimal control of growth and climate change: Exploration of scenarios. In J. Crespo Cuaresma, T. Palokangas, \& A. Tarasyev (Eds.), Green Growth and Sustainable Development, pp. 113-139. Berlin: Springer.

Moser, E., Prskawetz, A. \& Tragler, G. (2011). Environmental regulations, abatement and economic growth. Vienna: Vienna University of Technology. Research Report 2011-02 March working paper accessed July 13, 2016 at http://orcos.tuwien.ac.at/fileadmin/t/orcos/Research_Reports/2011-02\%20GT.pdf 
Nordhaus, W.D. (1994). Mapping the global commons: The economics of climate change. Cambridge, MA: MIT Press.

Nordhaus, W.D. (2008). A question of balance: Weighting the options on global warming. New Haven: Yale University Press.

Nordhaus, W.D. \& Boyer, J. (2001). Warming the world economic models of global and warming. Cambridge, MA: MIT Press.

Oppenheimer, M., O'Neill, B.C., Webster, M. \& Agrawal, S. (2011). Climate change: The limits of consensus. Science, 317, 5844, 1505-1506.

Puaschunder, J. M. (2016a). Intergenerational climate change burden sharing: An economics of climate stability research agenda proposal. Global Journal of Management and Business Research: Economics and Commerce, 16, 3, 31-38.

Puaschunder, J. M. (2016b). Proceedings of the 2016 Young Scientists Summer Program Conference, International Institute for Applied Systems Analysis (IIASA), Laxenburg, Austria.

Ramsey, F.P. (1928). A mathematical theory of saving. Economic Journal, 38, 152, 543-559.

Rawls, J. (1971). A theory of justice. Cambridge, MA: Harvard University Press.

Rovenskaya, E. (2005). Sensitivity and cost-benefit analyses of emission-constrained technological growth under uncertainty in natural emission. Laxenburg, Austria: International Institute for Applied Systems Analysis Interim Report, September 2005.

Rovenskaya, E. (2008). Optimal economic growth under stochastic environmental impact: Sensitivity analysis. Laxenburg, Austria: International Institute for Applied Systems Analysis Interim Report, January 2008.

Sachs, J.D. (2014). Climate change and intergenerational well-being. In Bernard, L. \& Semmler, W. (Eds.), The Oxford Handbook of the Macroeconomics of Global Warming, pp. 248-259. Oxford: Oxford University Press.

Schmitz, G. (1991). Klimatheorie und -modellierung. In Hupfer, P. (Ed.), Das Klimasystem der Erde: Diagnose und Modellierung, Schwankungen und Wirkungen, pp. 181-217. Berlin: Akademie.

Semmler, W., Greiner, A., Diallo, B., Rajaram, A. \& Rezai, A. (2011). Fiscal policy, public expenditure composition and growth: Theory and empirics. Aestimatio: The IEB International Journal of Finance, 2, 48-89.

Semmler, W., Greiner, A., Diallo, B., Rezai, A.,\& Rajaram, A. (2007). Fiscal policy, public expenditure composition, and growth: Theory and empirics. The World Bank: Africa Region. Public Sector Governance Department Policy Research Working Paper 4405.

Smulders, S. (1995). Entropy, environment, and endogenous growth. International Tax and Public Finance, 2, 319-340.

The World Bank (2015). Green bonds attract private sector climate finance, World Bank Brief, 2015.

The World Economic Forum 2015 Report. Davos, Switzerland: World Economic Forum. 